\section{Associate Professor Alina Irina POPESCU, PhD \\ E-mail: alina.popescu@rei.ase.ro \\ Department of International Business and Economics \\ The Bucharest University of Economic Studies}

\title{
BUSINESS FORMATION DURING THE CORONAVIRUS PANDEMIC. A REGIONAL ANALYSIS CONSIDERING KNOWLEDGE AND TECHNOLOGICAL INTENSITY
}

Abstract. The topic of business formation is especially relevant today when humankind faces the biggest global crisis since World War II. The protection of jobs and workers is vital, and a plethora of measures have been implemented since the outburst of the coronavirus pandemic in 2020. Remote activity interactions, whether forced or voluntary, shaped the economic landscape, restructured organizations, and reallocated the workforce across industries. In such context, this study investigates the dynamics of business formation in Romania throughout the first year of the coronavirus pandemic. Business formation registered significant growth in the second half of 2020, surpassing the level of the previous year. The analysis is performed at regional level, for 42 administrative regions, considering the intensity of knowledge and technology levels of industries in which new business was formed, according to the Eurostat classification of industries. The score of Knowledge and Technology Intensity (KTIRS) is calculated at regional level. The clustering of regions resulted in 6 cluster templates, given the industrial structure of new business formation.

Keywords: Business formation, Entrepreneurship, Regional analysis, Cluster analysis, Knowledge and Technology Intensity Score (KTIRS), Coronavirus pandemic (COVID-19).

\section{JEL Classification: M13, R12, C38}

\section{Introduction}

Like most other business aspects, business formation has been significantly impacted by the novel coronavirus pandemic. Empirical evidence regarding this matter shows contrasting results. While the most documented evidence that comes from the United States indicates a surge in business formation in these states (see for instance Haltiwanger, 2020), evidence from other mature economies (e.g. The Netherlands, Spain, Portugal or Germany) indicates a significant downturn in business formation (see for instance OECD, 2021). The recovery in business formation rates after the second half of 2020 is highly heterogeneous across

DOI: $10.24818 / 18423264 / 55.4 .21 .13$ 
Alina Irina Popescu

countries, with both short and long-term implications on employment, welfare, and growth.

In our analysis, we focus on new firms registered in Romania over the first year of the novel coronavirus pandemic (2020) to analyse the new business dynamism and patterns, to identify structural changes at industry level induced by the re-allocative shock of the COVID-19 pandemic. The shifts towards remote activity interactions between business and consumers and business and workers boosted business activity in trade (both retail and wholesale), especially in ecommerce, and in a wide variety of trade connected industries, and well as in construction and on-demand services.

Recent studies (see for instance OECD, 2021; Haltiwanger, 2020) reported that business formation in industries with higher technological and knowledge intensities was less affected during the novel coronavirus pandemic lockdowns from 2020, while business formation in industries relying in close personal contact was significantly impoverished. In this study, we observe the knowledge and technology intensity of the economic sectors subject to new business establishment, we aggregate firm level data to compute a score of knowledge and technology intensity for Romanian regions observing the Eurostat industries classification at 2 digits NACE 2.

A Ward-linkage cluster analysis on Romanian regions was performed considering the industrial structure of business formation and the associated knowledge and technology intensity. Cluster templates for Romanian regions are provided. The results show that four out of six clusters contain industries that are not characterized by high technology levels, nor do they require specialized knowledge, high skills, or sophistication.

Specifically, we attempt to discuss the following research questions: RQ1: Can it be observed that business formation during pandemic in Romania has specific development patterns and dynamics across regions? RQ2: Can a change in the industrial structure be observed in business formation during pandemic across Romanian regions? RQ3: To which extent regional distributions of knowledge and technology can be uncovered considering the business formation during pandemic? RQ4: What cluster templates can be identified for Romanian regions given the knowledge and technology intensity of business formation during pandemic?

The paper is structured as follows. In section 1, we emphasize the background of our research, by reviewing the scientific literature that is particularly relevant to business formation, its dynamics during the current coronavirus pandemics, and the theoretical rationales of this research. Next, the methodological section follows (Section 2). Here, we detail our three-step research approach (step 1. Descriptive and exploratory analysis; step 2. Regional score of knowledge and technology intensity; and step 3. Clustering analysis of regions). Section 3 presents and discusses our research results. Finally, Section 4 concludes our study. 
Business Formation during the Coronavirus Pandemic. A Regional Analysis Considering Knowledge and Technology Intensity

\section{Theoretical Background}

The coronavirus pandemic has had indisputable consequences on all aspects of life. Numerous studies investigated how governments have tailored their response to this global health crisis through public policies in the fields of: public health (e.g., Tulenko \& Vervoort, 2020), education (e.g. Subramanian et al., 2020), environment (e.g. Helm, 2020). Pandemic's economic impact was thoroughly investigated from a variety of stances and perspectives, especially with regard to the macroeconomic impact (e.g. Zinecker et al., 2021) or in relation to specific sectors such as tourism (e.g., Zenker \& Kock, 2020), trade and global supply chains (e.g., Ivanov, 2020), budgetary and monetary policies (e.g. Huynh et al., 2021), labour market and workforce (Achdut, 2020).

What is clear though from previous research is that the current coronavirus pandemic shook not only the national economies taken individually, but also the global economy to such an extent that it merely severed the deep ties among national economies developed by the globalization. Therefore, in this uncertain period of global pandemic, it is important to understand the role of new firms in fostering economic growth, and the ways in which they participate to the economic restructuring and transformation.

Business formation in advanced economies was negatively affected by the pandemic (Calvino et al., 2020). Studies conducted in European Union countries, for instance, reported several measures promoted by the European Commission and national governments to maintain employment and avoid lay-offs. In this sense, Zinecker et al. (2021) reported SMEs supporting measures such as: working capital loans, deferred payments for taxes or social security contributions, funds for the implementation of part-time working schemes, and other containment measures. By contrast to the situation in Europe, the scale of business formation in the United States during pandemic indicated a surge in new business applications in the United States of America. Researchers argued that US job retention schemes had a limited effect. Therefore, by failing to supress employment declines, entrepreneurship by necessity exploded, surging business formation in the United States during 2020 (Alder, 2020; Haltiwanger, 2020).

In the attempt to investigate the economic transformation during the novel coronavirus pandemic, we are focusing on newly established firms for several reasons. First, business formation is a critical driver of economic growth. Additionally, it has been suggested that newly born and young firms are an important creator of jobs in an economy (Decker et al., 2014). Previous research conducted in the United States correlated the surge in business formation with job losses at the state level (Djankov and Zhang, 2021). However, these firms' survival rates are low. According to Sedláček and Sterk (2020) newly established firms exhibit a higher rate of exit, but the surviving young businesses demonstrate high aggregate productivity growth. Other studies argued that the growth rate is concentrated into a small share of fast-growing start-ups. More precisely, only a small group of newly established firms shows an exceptional growth rate and 
Alina Irina Popescu

growth potential (the so called 'gazelles') from their inception that account for about 60 percent of aggregate employment growth, 50 percent of aggregate output growth, and 40 percent of aggregate growth in total factor productivity (Haltiwanger et al., 2017).

Second, evidence has shown that new-born firms prove high levels of flexibility, agility, and adaptability, surpassing incumbent firms' performance (Haltiwanger et al., 2013). Particularly in times of crisis, new firms' dynamism, adaptability, and flexibility enable the economy to quickly adapt to changing economic circumstances and to recover from recessions in a viable manner.

Thirdly, new firms (or start-ups) are generally associated with technology, specialized knowledge, and innovation. The link between entrepreneurial behaviour - which underlies business development, and innovation was clearly established. Similarly, it has been argued that new-born firms are likely to introduce innovations onto the markets, especially radical or even disruptive innovations, thus contributing to economic growth (Audretsch et al., 2005).

In general, the common wisdom expects new-born firms to develop and market innovative products that disrupt incumbents' position, and therefore, they are seen as the main source of creative destruction. Many radical innovations were introduced by new firms generated a wide debate on what has been proposed as the 'knowledge spillover theory of entrepreneurship' (see Audretsch et al., 2005). Contrasting this belief, concepts like 'replicative' entrepreneurship or 'necessity entrepreneurship' have been discussed in the entrepreneurship literature, gaining arguments with the current novel coronavirus pandemic. However, it is also true that recessions or crises stimulate innovation, proven by the fact that the greatest disruptors of traditional industries were born around the previous economic recession (e.g. Uber, Airbnb, Venmo). In fact, a small share of business formation from the United States was found to be truly innovation by Hurst and Pugsley (2011).

Finally, the formation, survival and growth of new businesses are affected by the regional conditions. Previous efforts to link variations in new business formation with regional specific characteristics revealed that business formation is influenced by region-specific characteristics and attributes (e.g. Audretsch \& Lehmann, 2005). The common wisdom is that regions with higher level of technological development and innovation present higher growth and business formation (Braunerhjelm et al., 2010). However, significant differences between regions regarding their effect on business creation were found by Fritsch \& Schroeter (2011). Attempting an explanation, they propose a set of key characteristics of regions that may critically impact regional innovativeness and innovative business formation that includes: the availability of important resources (e.g. capital, labour, services), the regional knowledge base (e.g. existence of universities and research institutes, existence of other innovative firms), and the intensity of the regional knowledge spillovers (Fritsch \& Schroeter, 2011, pp. 385386). 
Business Formation during the Coronavirus Pandemic. A Regional Analysis Considering Knowledge and Technology Intensity

As previously summarized, the literature includes contrasting views on business formation's contribution to growth and employment, its dynamics, reasons, or degree of innovativeness. Additionally, the novel coronavirus pandemic influenced the evolution of business formation in different directions, in different countries. What appears to be a consensus in the extant literature is that business formation is localized and regionally embedded. Having this in mind, we proceed to analyse business formation during the year 2020 in Romania, at regional level. We assess the knowledge and technology intensity of business creation at regional level, and we propose cluster templates given the regional industrial structure.

\section{Research Methodology}

The research used quantitative research methods. We use monthly data on new business formation in Romania by location and by economic activity using NACE Rev.2 at 2 digits, for the period January-December 2020. Our sample consists of 80,194 new firms registered in Romania during the year of 2020. Data were provided for academic research purposes by a private company that acquires firm statistical data from the Romanian Trade Registry.

The first step of the analysis consisted of the descriptive analysis of the business formation during pandemic in Romania. This stage had an exploratory purpose to identify the dynamics of business formation during pandemic, as opposed to the performance registered in the previous year (2020 versus 2019).

The second step of the analysis was to determine the level of knowledge and technology induced by new business formation during the year of 2020. In order to do that, we calculate the knowledge and technology intensity regional score (KTIRS). The reason for the construction of KTIRS is twofold: First, business formation is generally associated with 'startups', which, in turn, are associated with technological advancement and innovation. Secondly, business formation during pandemic is considered to have technology incorporated to a large extent to comply to remote performance of business activities.

The knowledge intensity and technological classifications used follow Eurostat taxonomies. According to Eurostat $(2016,2020)$, manufacturing industries are classified as: High-Technology (HT), Medium High-Technology (MHT), Medium Low-Technology (MLT) and Low-Technology (LT) industries given their NACE code. Services are grouped into Knowledge-Intensive Services (KIS) and Less Knowledge-Intensive Services (LKIS) according to the share of tertiaryeducated persons at the NACE Rev2 2-digit level.

Using this approach, we compute the values at the level of Romanian administrative regions (more specifically for 41 Romanian regions plus Bucharest, the capital city, which is a distinctive administrative region). The rationale was to identify to which extent the pandemics influenced the knowledge and technology intensity of business formation in Romania.

The regional score of knowledge and technological intensity (KTIRS) was calculated using the following formula: 
Alina Irina Popescu

$$
\text { Regional Score }_{i}=\frac{\sum\left(n_{i j} * k_{j}\right)}{\sum n_{i}}
$$

where:

$i$ represents the region, in this study $i$ takes values from 1 to 42 (the number of Romanian administrative regions, more precisely 41 counties and Bucharest),

$j$ represents the NACE Rev. 2 code at 2 digits, and rages from 1 to 99;

$k$ represents the score attributed to an economic activity classified by NACE, and it takes the following values: 1 for LT, 2 for MLT and LKIS, 3 for MHT, and 4 for HT and KIS.

The third step of the research involved the clustering of Romanian regions given the knowledge and technology intensity scores calculated based on new business formation during the entire year of 2020 significantly marked by the coronavirus pandemic. Cluster templates (groups of regions) were formed according to the composition of the industries showing the similarity of industrial structure given the knowledge and technology intensity of Romanian regions. The inquiry with regard to the third step was to look deeper by investigating the technology and knowledge intensity levels of the industries (sectoral composition of clusters of regions) within identified cluster templates.

\section{Results and Discussion}

We start the presentation of our empirical results with a descriptive analysis of the business formation in Romania during 2020, the year that was marked entirely by the coronavirus pandemic, the first research step.

In terms of business formation, a consolidation trend was shaping the Romanian new firm formation landscape in 2019, ending a 10-year period of new business growth after the outbreak of the global economic and financial crisis. Business formation registered in 2019 a decreasing trend in Romania, as Figure no. 1A clearly shows. The number of active firms at the end of 2019 was the highest ever registered, while the new entrepreneurial appetite was slowing down. However, data on new firm registrations show a positive onset in January-February 2020, a period in which the first news on the coronavirus epidemic, at that time, travelled the globe. Uncertainty coupled with government's lockdown restrictions including stay-at-home orders led to a dramatic fall in business formation during MarchApril 2020. The year-on-year variation in April was -.77 percentage points, as shown by Figure no. 1B.

Although significantly depressed, business formation in Romania did not cease in the immediate wake of the shock created by the coronavirus pandemic. Business formation started to recover in June 2020, surpassing both year-earlier values and the pace of business formation in 2019. This surge in new firm formation might be 
Business Formation during the Coronavirus Pandemic. A Regional Analysis Considering Knowledge and Technology Intensity

particularly surprising, especially in the context of restricted mobility and stay-athome orders, job protection measures (such as: technical unemployment, situation in which the employee is entitled to receive at least .75 of salary income in the event of the temporary reduction or cease of work activity, or remote work approved for sectors at risk like education, health or public administration), or absence of supporting measures for new entrepreneurship.
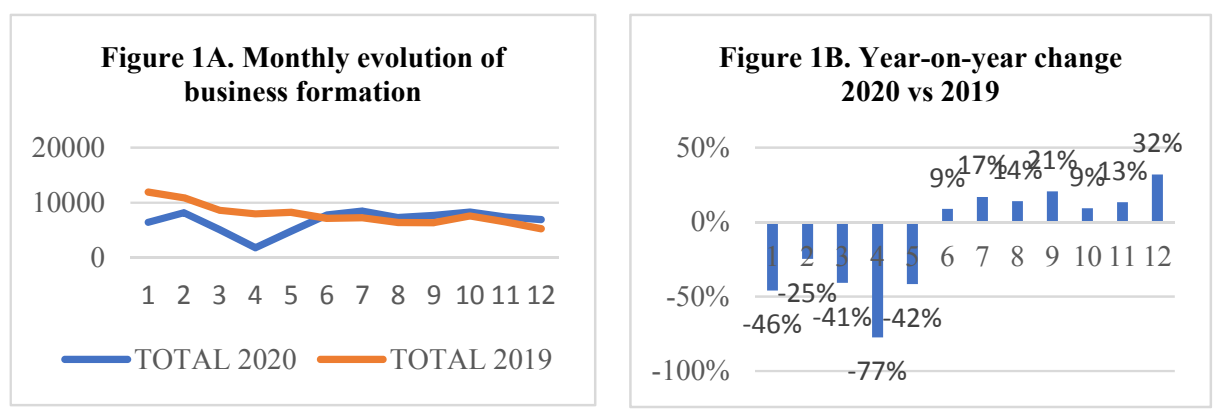

Figure 1. Evolution of business formation in Romania (2020 / 2019)

Source: own research

An estimated business formation of 80,194 new firms in the year of 2020 in Romania raised the total number of firms to a historical high of 1.04 million active firms (The Romanian Trade Registry, 2021).

However, business formation in the pandemic time has been uneven across Romanian administrative regions (counties), as showed by Figure no. 2. We note that it follows the earlier established pattern of pre-pandemic period in the sense that it is highly concentrated in the large urban poles of Romania. Over one fifth of the total number of new-born firms during 2020 was registered in Bucharest, the capital city of Romania. Next come five counties that form the leading platoon. This is formed by Ilfov with a share of $6 \%$ from the total business formation (Ilfov is the surrounding county of Bucharest), followed by Cluj with a share of $5 \%$ from the total business formation, Timiș with a share of $5 \%$ from the total business formation, Constanța with a share of $4 \%$, and Iași with a share of $4 \%$. The largest cities of Romania are located in these counties, acting as growth poles for the development of the historic regions of Romania (i.e. Cluj-Napoca, Timișoara, Constanța and Iași). Nevertheless, when considering the stock of human capital, the analysis of business formation per 1,000 inhabitants at county level show a more uniform distribution of new-born firms across Romanian counties. 
Alina Irina Popescu

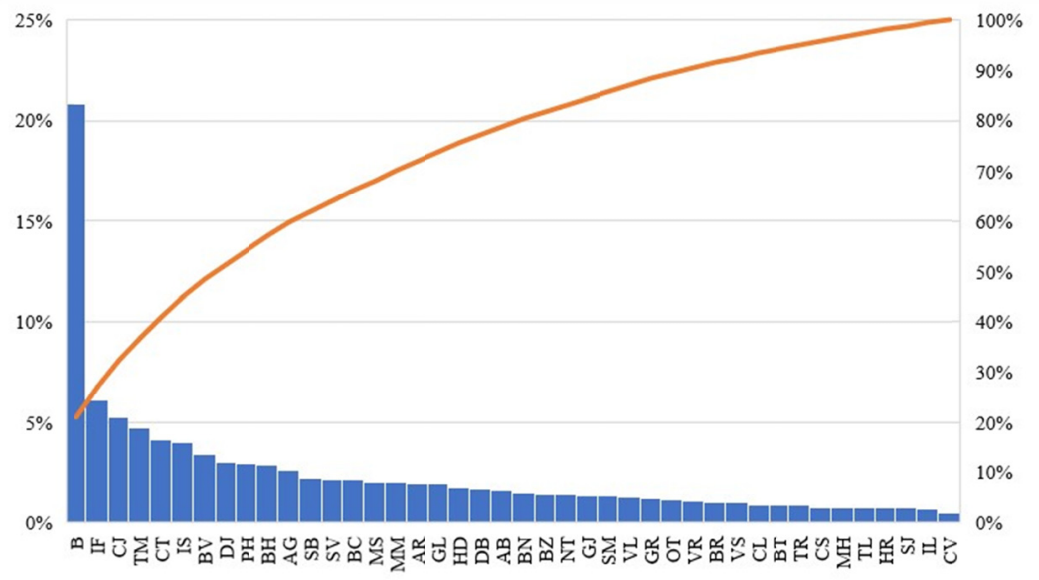

Figure 2. Business formation in Romanian counties (\% of total registered firms)

Source: own research

Further on, business formation by economic activity and industry during the coronavirus pandemic reveals consistent shifts triggered by remote activity interactions, whether forced or voluntary, between organisations and workers (i.e., remote work) or organisations and consumers (i.e., electronic commerce with delivery or pick-up points). A surge in new firm registrations was recorded in particular sectors that support remote human interaction, leading to a sudden and ongoing restructuring of the economy induced by the pandemic (the so-called reallocative shock).

The pandemic shifted business operation and consumption patterns. Results show that business formation was dominant in three spheres of economic activity: trade, construction, and personalized services, plus their support economic activities, as shown by Figure no. 3. Firstly, newly born firms in retail trade accounted for $15 \%$ of the total registered new firms in 2020, mainly being determined by the non-store retail trade. EU statistics show that, in 2020, the percentage of firms with ecommerce sales of at least $1 \%$ of turnover increased in Romania by $50 \%$ compared to 2019, and that the highest growth was registered by small firms. This is the highest increase at EU level, where the average increase was of $6.67 \%$ (Eurostat, 2021).

Somehow intuitive, this impact is larger than anyone could have anticipated before. Small, agile, and flexible on-line retailers emerged, putting serious competitive pressure on large, more traditional, and less flexible, brick-and-mortar retailers. Importantly, retail trade boom extended to other industries, such as: wholesale trade; land transport; retail, wholesale, and repair of motor vehicles; postal and courier activities; food and beverages services activities. 
Business Formation during the Coronavirus Pandemic. A Regional Analysis Considering Knowledge and Technology Intensity

Secondly, the construction sector generated great business formation during 2020 in Romania. The advance of residential buildings is noticed in the circumstances in which most people were forced to perform their activities remotely from home, but at the same time, to maintain distance between generations. The spike in this sector propagated to other economic activities, as well, especially to architecture, technical engineering, real estate, services to buildings, building administration, or materials transport. Thirdly, specialized services also experienced a rapid rebound. Here, newly born firms were mainly providing services such as: computer programming, consultancy and related activities; human health activities; education; sports, recreation and entertainment; other personal services (e.g. hairdressing, housekeeping, beauty treatments, and funerals).

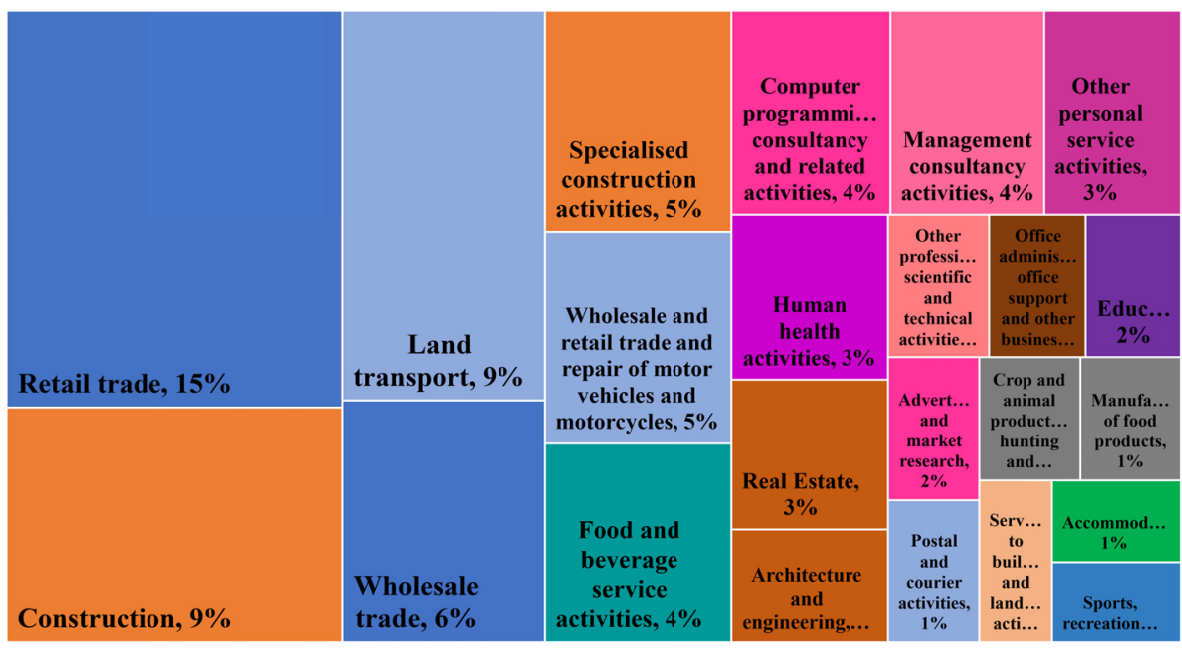

Figure 3. Sectoral analysis of business formation in Romania (share in total business formation during 2020)

Source: own research

The growth registered by these economic activities shows shifts in business models and business operation, and changes to consumers' lifestyles and consumption patterns. Importantly, in terms of jobs, business formation during pandemic shows re-allocative effects of labour. Sectors with economic activities that are misfit to social distancing are in great danger, and inter-sectoral job reallocation is a result of the pandemic shock. Reduced mobility has generated a massive overall fall in the aggregate demand, with severe labour market disruptions.

Further on, we explore the knowledge and technology intensity of new business established during the year 2020, at regional level (research step 2). As detailed in the methodological section, we calculate a knowledge and technology intensity score (KTIRS) observing the Eurostat $(2016,2020)$ classifications of economic 
activities (i.e. HT, MHT, MLT, LT, KIS, and LKIS) at 2 digits based on NACE Rev. 2.

Figure no. 4 illustrates the knowledge and technology intensity regional scores (KTIRS) for Romanian administrative regions. We observe that the calculated regional scores range between 2.1372 and 2.7022 . This shows a general medium level of knowledge and technology intensity, where the lowest score (2.1372) corresponds to a medium-low knowledge and technology intensity, and the highest score (2.7022) is closer to the threshold for a medium-high knowledge and technology intensity.

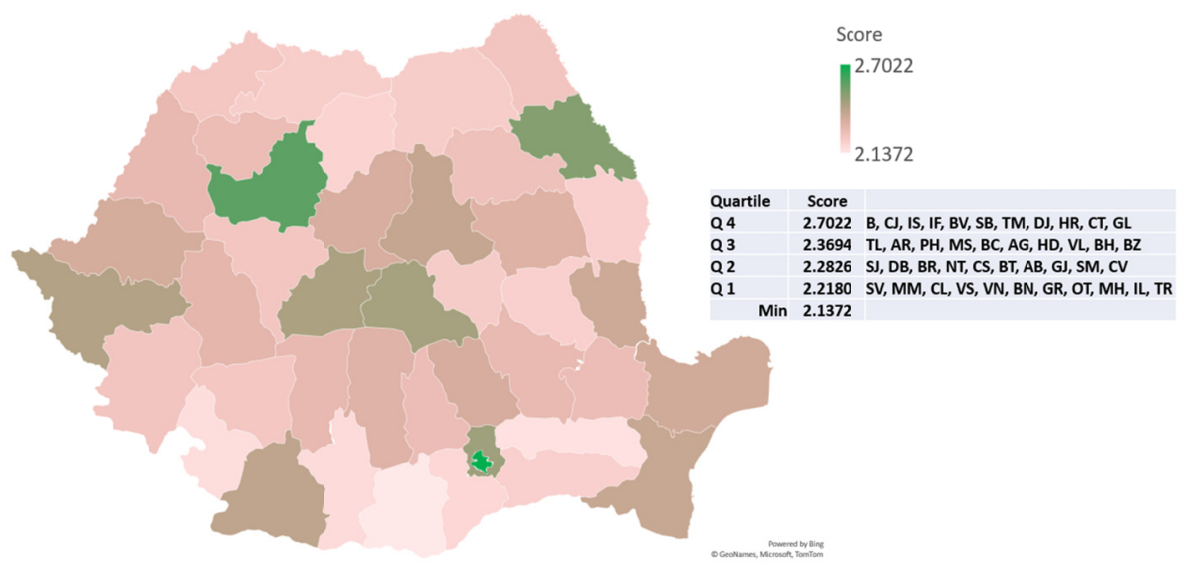

Figure 4. Knowledge and Technology Intensity Regional Scores for Romanian regions (counties)

Source: own research

Quartile analysis reveals the KTIRS performance of regions. Top performers (Q4) include both regions that have traditionally acted as growth poles (e.g. Bucharest, Cluj, Iași, Brașov, Timiș), and regions that have more recently developed (e.g. Ilfov, Dolj). Regions included in the $3^{\text {rd }}$ quartile neighbour top performing regions. Their geographic position resembles a belt, bordered on the West by the regions of Arad and Bihor, and on the East by Tulcea. Possible spillover effects from top performing regions to these regions require further investigation. Regions included in the $2^{\text {nd }}$ quartile are dispersed across all the territory of Romania. However, a closer look at their geographic position reveals two North-South transverse lines. One transverse line includes the regions of Satu Mare, Sălaj, Alba, Gorj and CarașSeverin, while the second line includes the regions of Botoșani, Neamț, Covasna, Dâmbovița and Brăila. The lowest performing regions in terms of KTIRS are peripherally located in the North (i.e., Maramureș, Bistrița-Năsăud, Suceava), East (i.e., Vaslui, Vrancea), and predominantly in the South (i.e. Mehedinți, Olt, Teleorman, Giurgiu, Călărași, Ialomița) of the Romanian territory. 
Business Formation during the Coronavirus Pandemic. A Regional Analysis Considering Knowledge and Technology Intensity

Findings also show that the regions that have been playing the role of economic growth poles not only attracted the largest number of new businesses that were formed during the year of 2020 in Romania, but also that these new-born firms were established in industries characterized by a higher knowledge and technology intensity. The largest number of firms (business formation) during 2020 was established in Bucharest (16,710 firms) with an average KTIRS of 2.7021. The scatter plot for Romanian counties is shown by Figure no. 5 .

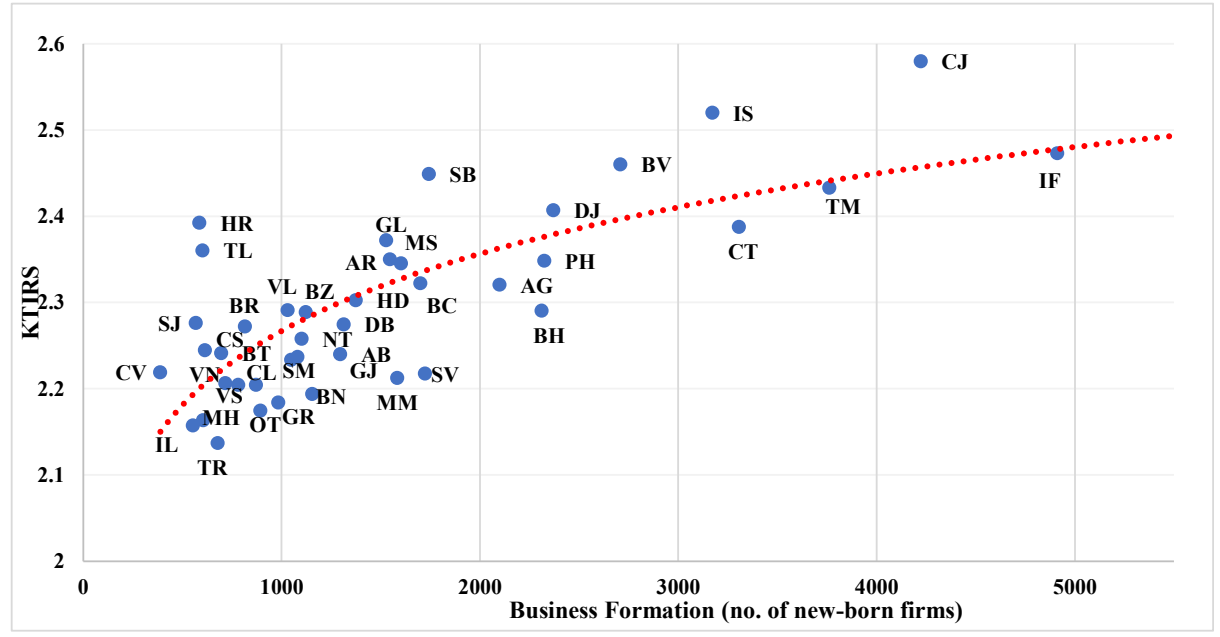

Figure 5. Business formation versus KTIRS score (2020)

Source: own research

The Ward's linkage cluster analysis of regions considering the knowledge and technology intensity scores (KTIRS) calculated based on new business formation during the entire year of 2020 identified 6 cluster templates (groups of regions) based on the composition of the industries subject to new business formation during 2020 (research step 3). The cluster template shows the regional industrial structure with regard to sectoral knowledge and technology intensity. The clusters and the associated summary statistics are shown by Table no. 1.

The $1^{\text {st }}$ identified cluster comprised of Bucharest, the capital city of Romania. With a predominance of new business formation during 2020 in services ( 85 percent), Bucharest shows a particular industrial structure when compared to the rest of the counties: 36.3 percent of the investigated new-born firms were established in KIS industries, 48.7 percent of new-born firms were registered in LKIS industries, 2.8 percent in low-technology (LT) industries, and less than 1 percent in HT or MHT. However, due to the large number of newly established firms during 2020, Bucharest is the top performer among all Romanian regions in terms of KTIRS. 
Alina Irina Popescu

The $2^{\text {nd }}$ cluster included the regions of Cluj, Constanța, Timiș, and Ilfov. Similar to cluster 1, this cluster template shows the predominance of business formation in services over manufacturing. In average, 27.9 percent of the investigated new-born firms were established in KIS industries, 51.1 percent of these firms in LKIS industries, 4.7 percent of new-born firms in LT industries, $1.5 \%$ of new-born firms in MLT industries, and less than 1 percent in HT industries.

Table 1. Summary statistics by clusters for business formation during 2020

\begin{tabular}{|c|c|c|c|c|c|c|c|}
\hline \# & & HT & MHT & MLT & LT & KIS & LKIS \\
\hline \multirow{4}{*}{$\begin{array}{l}\text { Cluster } 1 \\
\text { B }\end{array}$} & Min & 14 & 43 & 117 & 468 & 6065 & 8146 \\
\hline & Mean & 14 & 43 & 117 & 468 & 6065 & 8146 \\
\hline & Max & 14 & 43 & 117 & 468 & 6065 & 8146 \\
\hline & $\mathrm{N}$ & 1 & 1 & 1 & 1 & 1 & 1 \\
\hline \multirow{4}{*}{$\begin{array}{l}\text { Cluster } 2 \\
\text { CJ, CT, TM, IF }\end{array}$} & Min & 0 & 12 & 51 & 184 & 722 & 1831 \\
\hline & Mean & 1.5 & 15.75 & 64.5 & 206.75 & 1054.5 & 2095 \\
\hline & $\operatorname{Max}$ & 5 & 20 & 72 & 229 & 1330 & 2765 \\
\hline & $\mathrm{N}$ & 4 & 4 & 4 & 4 & 4 & 4 \\
\hline \multirow{4}{*}{$\begin{array}{l}\text { Cluster } 3 \\
\text { AG, BV, BH, DJ, } \\
\text { IS, PH }\end{array}$} & Min & 0 & 2 & 39 & 133 & 413 & 1169 \\
\hline & Mean & 1 & 8.333 & 57.5 & 164.16 & 578.333 & 1298.167 \\
\hline & Max & 2 & 12 & 67 & 206 & 922 & 1432 \\
\hline & $\mathrm{N}$ & 6 & 6 & 6 & 6 & 6 & 6 \\
\hline \multirow{4}{*}{$\begin{array}{l}\text { Cluster } 4 \\
\text { BT, CL, CS, CV, } \\
\text { HR, IL, MH, SJ, } \\
\text { TL, TR, VS }\end{array}$} & Min & 0 & 0 & 5 & 37 & 60 & 218 \\
\hline & Mean & .363 & 2.181 & 14.727 & 61.818 & 101.909 & 341.18 \\
\hline & Max & 2 & 5 & 22 & 89 & 148 & 438 \\
\hline & $\mathrm{N}$ & 11 & 11 & 11 & 11 & 11 & 11 \\
\hline \multirow{4}{*}{$\begin{array}{l}\text { Cluster } 5 \\
\text { AB, AR, BC, DB, } \\
\text { GL, HD, MM, } \\
\text { MS, SB, SV }\end{array}$} & Min & 0 & 2 & 17 & 85 & 214 & 686 \\
\hline & Mean & .7 & 5.7 & 34.9 & 120.9 & 296.7 & 826.8 \\
\hline & Max & 2 & 8 & 53 & 154 & 446 & 977 \\
\hline & $\mathrm{N}$ & 10 & 10 & 10 & 10 & 10 & 10 \\
\hline \multirow{4}{*}{$\begin{array}{l}\text { Cluster } 6 \\
\text { BN, BR, BZ, GJ, } \\
\text { GR, NT, OT, SM, } \\
\text { VL, VN }\end{array}$} & Min & 0 & 0 & 12 & 68 & 117 & 478 \\
\hline & Mean & .5 & 3 & 26.2 & 86.8 & 159.9 & 557.9 \\
\hline & Max & 2 & 6 & 56 & 118 & 206 & 660 \\
\hline & $\mathrm{N}$ & 10 & 10 & 10 & 10 & 10 & 10 \\
\hline \multirow[t]{4}{*}{ Total } & Min & 0 & 0 & 5 & 37 & 60 & 218 \\
\hline & Mean & 1 & 6.357143 & 35.548 & 119.928 & 462.857 & 997.976 \\
\hline & $\operatorname{Max}$ & 14 & 43 & 117 & 468 & 6065 & 8146 \\
\hline & $\mathrm{N}$ & 42 & 42 & 42 & 42 & 42 & 42 \\
\hline
\end{tabular}

The $3^{\text {rd }}$ cluster grouped 6 regions that showed similarity in terms of the technological and knowledge intensity of the industrial structure. These counties exhibit larger shares of business formation in LKIS and LT industries, as compared to the counties from the previous clusters. In average, 53.4 percent of new-born firms were established in LKIS industries, 22.7 percent of new-born firms in KIS industries, 6.6 percent in LT industries, and an insignificant number of firm registrations were in HT industries. Cluster 4 included 10 regions. In average, 55.3 percent of new-born firms were established in LKIS industries, 16.6 percent in KIS industries, 10.0 percent in LT industries, 2.4 percent in MLT, less than 1 percent in HT and MHT industries. Clusters 5 and 6 grouped 10 regions each. Their cluster 
Business Formation during the Coronavirus Pandemic. A Regional Analysis Considering Knowledge and Technology Intensity

templates show that around half of the newly established firms during the pandemic in the regions included here were registered in LKIS sectors, between 15 percent (for Cluster 5) and 20 percent (for Cluster 6) in KIS sectors, around 8 percent of new-born firms from these regions were registered in LT industries, and less than 1 percent in HT and MHT industries. The industrial similarity of business formation between regions can also be observed from the dendrogram of the cluster analysis (Figure no. 6). We observe once again the large dissimilarity between Bucharest, and the rest of the country.

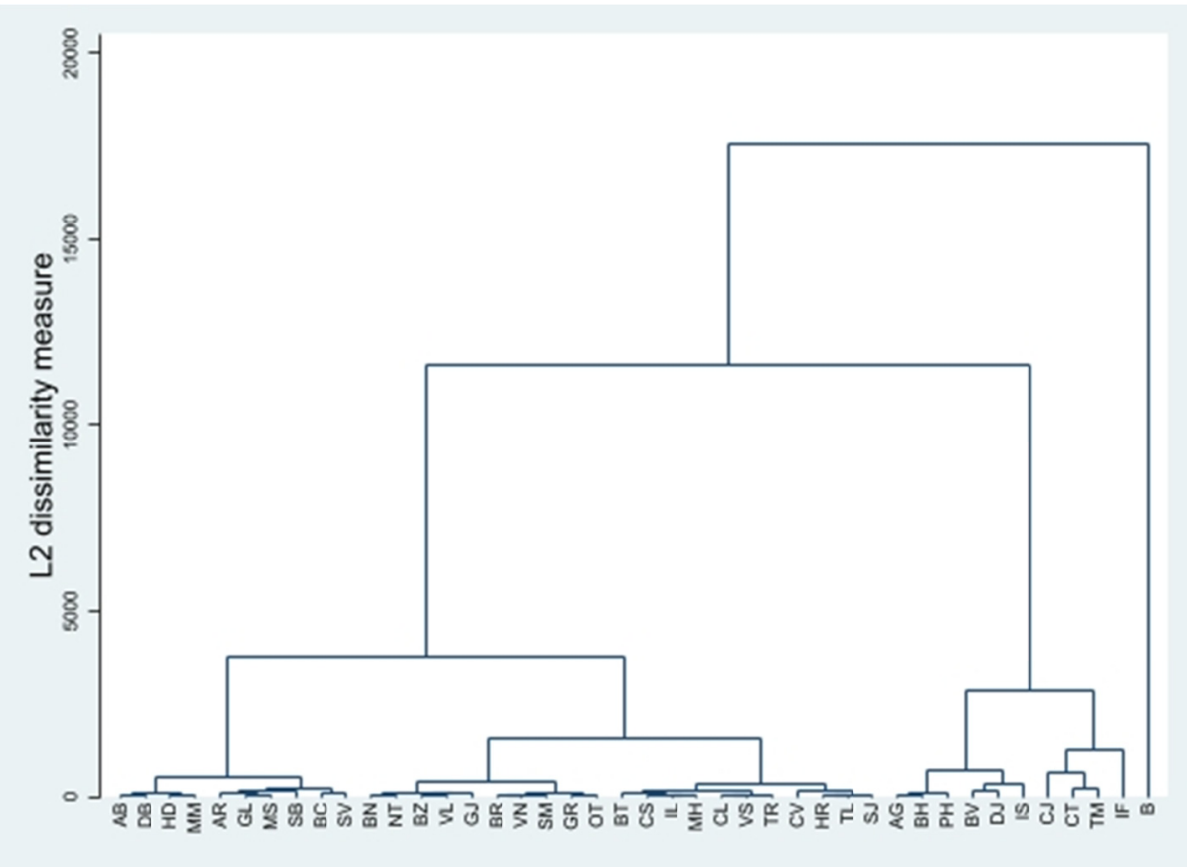

Figure 6. Cluster Dendrogram

This study investigated the dynamics of new business formation in Romania during the year of 2020 which was under the auspices of the global coronavirus pandemic. Business formation agglomerated in Bucharest, in its surrounding region Ilfov, and in the regions that traditionally played economic growth roles throughout the modern history of Romania. Except for Bucharest, we uncovered a wider similarity between regions in terms of knowledge and technological intensity based on our KTIRS calculation (results range from 2.1372 to 2.7022) and clustering analysis.

\section{Conclusion}

The novel coronavirus pandemic has led to widespread negative effects in the economic activity, with disruptions in the business formation. We focused on business formation throughout this global health crisis given the broad consensus 
Alina Irina Popescu

that the lack of start-up activity and business dynamism undermines the long-term economic growth. We argue that business formation played a significant role in coping with the re-allocative shock of the novel coronavirus pandemics. Through our analysis of business formation per sector of economic activity (classified according to NACE Rev.2) we develop evidence on the extent and nature of the reallocation of jobs across sectors generated by the lockdown measures (including remote work). Results show that business formation was dominant in three spheres of economic activity: trade and trade-related activities (over 36 percent), personalized services (over 23 percent), and construction and construction-related activities (over 21 percent). Over half of new business formed during 2020 in Romania was recorded in service sectors. Although these evolutions are somehow intuitive, the scale is larger than anticipated before.

The dominant view according to which business formation, in general, and in the current context of remote interaction imposed by the novel coronavirus pandemic, in particular, is linked with innovation and technology, was assessed through the computation of a knowledge and technology regional score (KTIRS) for new business formation in Romanian regions. Although the empirics are limited to Romanian regions, this method's external validity can be easily confirmed by further research investigating other territories. Findings reveal a medium-low level of knowledge and technology intensity of business formation, with between county variation. The highest score was registered by the capital of Romania, Bucharest, while the lowest performers are peripheral regions from South, East and North of Romania. The spatial distribution of regions considering their KTIRS provide several indications of knowledge spillovers across regions. This requires further research to document and test the knowledge spillover theory of entrepreneurship in Romanian regions.

Our study provided the industrial structure assessed according to Eurostat taxonomies of knowledge intensity and technology level and the regional distribution of cluster templates. In this respect, a first conclusion is that Romanian regions have registered business formation mainly in service sectors with low knowledge intensities. This sectors (abbreviated LKIS) have a significant proportion in all cluster templates. Bucharest (cluster 1) forms a distinctive cluster, given its particular cluster template structure in which business formation in KIS sectors was 36.3 percent. This share of KIS new-born firm is the closest to that of the Cluj region (in which KIS new-born firms represent 31.5\%). The results of the clustering analysis performed on regions show that four out of six clusters include predominantly industries that are not characterized by high technology levels, nor do they require specialized knowledge, high skills, or sophistication.

Implications can be drawn for Romania's innovation, education, and regional development policies. One major policy recommendation involves the need to develop technological skills for entrepreneurs that facilitate the conditions for applying knowledge and technology in business endeavours. Human capital 
Business Formation during the Coronavirus Pandemic. A Regional Analysis Considering Knowledge and Technology Intensity

improvement through education in general, and science \& technology education in particular will enable the acquisition, usage and spread of new knowledge, technologies and developments, and will facility the creation of the conditions for higher knowledge and technologies intensities at regional level. Policy recommendations for stimulating the innovative capacity of new-born firms include the incentives to innovate, the strengthening of the institutional capacity, and the investment in education and research. Policies for regional development should address the regional imbalances, give special emphasis to regions where knowledge and technology intensity is low, and facilitate the inclusion of less technologized regions into the national system of innovation.

\section{ACKNOWLEDGEMENTS}

This work was supported by a grant from the Romanian Ministry of Research and Innovation, CNCS-UEFISCDI, research project number PN-III-P4-IDPCCF-2016-0166, type PNCDI III, research project title "ReGrowEUAdvancing ground-breaking research in regional growth and development theories, through a resilience approach: towards a convergent, balanced, and sustainable European Union".

\section{REFERENCES}

[1] Alder, S. (2020), Business Formation during the COVID-19 Pandemic; Center for Research on the Wisconsin Economy, UW-Madison, June 11, 2020;

[2] Achdut, L. (2020), The Labor Market in the Coronavirus Crisis; Israel Economic Review 18(1), pp. 59-79;

[3] Audretsch, D. \& Lehmann, E. (2005), Does the Knowledge Spillover Theory of Entrepreneurship Hold for Regions? Research Policy 34 (2005) 1191-1202;

[4] Audretsch, B., Keilbach, M. \& Lehmann, E. (2005), The Knowledge Spillover Theory of Entrepreneurship and Technological Diffusion. In Libecap, G. (editor); University Entrepreneurship and Technology Transfer: Process, Design, and Intellectual Property Advances in the Study of Entrepreneurship, Innovation and Economic Growth, Volume 16, 69-91. DOI:10.1016/S1048-4736(05)16003-2;

[5] Braunerhjelm, P., Acs, Z. J., Audretsch, D. B. \& Carlsson, B. (2010), The Missing Link: Knowledge Diffusion and Entrepreneurship in Endogenous Growth. Small Business Economics, 34(2), 105-125. https://doi.org/10.1007/s11187-009-9235-1; [6] Calvino et al. (2020), Challenges and Opportunities for Start-ups in the Time of COVID-19 | VOX, CEPR Policy Portal (voxeu.org);

[7] Decker, R., Haltiwanger, J., Jarmin, R., Miranda, J. (2014), The Role of Entrepreneurship in US Job Creation and Economic Dynamism; Journal of Economic Perspectives 28(3), pp. 3-24;

[8] Djankov, S. \& Zhang, E.(Y.) (2021), Startups in the United States during the Pandemic Reflect some Dynamism amid Job Losses. Policy Brief 21-9 May 2021, Peterson Institute for International Economics (PIIE), https://www.piie.com/sites/default/files/documents/pb21-9.pdf; 
Alina Irina Popescu

[9] Eurostat, 2016, 2020. High-tech industry and knowledge-intensive services https://ec.europa.eu/eurostat/databrowser/view/isoc_ec_eseln2/default/table?lang=en; [10] Eurostat, 2021.

https://ec.europa.eu/eurostat/databrowser/view/isoc_ec_eseln2/default/table?lang=en; [11]Fritsch, M. \& Schroeter, A. (2011), Why Does the Effect of New Business Formation Differ across Regions. Small Business Economics, 36(4), 383-400. https://doi.org/10.1007/s11187-009-9256-9;

[12]Haltiwanger, J. (2020), Entrepreneurship during the COVID-19 Pandemic: Evidence from the Business Formation Statistics;

[13]Haltiwanger, J, R Jarmin and J Miranda (2013), Who Creates Jobs? Small versus Large versus Young; The Review of Economics and Statistics 95(2): 347-61;

[14] Haltiwanger, J., R. Jarmin, R. Kulick and J. Miranda (2017), High Growth Firms: Contribution to Job, Output and Productivity Growth. In J Haltiwanger, E Hurst, J

Miranda and A Schoar (eds.), Measuring Entrepreneurial Businesses: Current Knowledge and Challenges, NBER Book Series Studies in Income and Wealth, Chicago: University of Chicago Press, pp. 11-62;

[15] Helm, D. (2020), The Environmental Impacts of the Coronavirus; Environmental and Resource Economics 76(1), pp. 21-38;

[16] Hurst, E. and B. Pugsley (2011), What Do Small Businesses Do; Brookings Papers on Economic Activity. Brookings Institution Press: Washington DC, pp. 73-142;

[17] Huynh, N., Dao, A., Nguyen, D. (2021), Openness, Economic Uncertainty, Government Responses, and International Financial Market Performance during the Coronavirus Pandemic; Journal of Behavioral and Experimental Finance 31,100536; [18] Ivanov, D. (2020), Predicting the Impacts of Epidemic Outbreaks on Global Supply Chains: A Simulation-Based Analysis on the Coronavirus Outbreak (COVID-19/SARS-

CoV-2) Case. Transportation Research Part E: Logistics and Transportation Review 136,101922;

[19] OECD (2021), Business Dynamism during the COVID-19 Pandemic: Which policies for an Inclusive Recovery?, Report, 18 February 2021;

[20] Sedláček, P.\& Sterk, V. (2020), Startups and Employment Following the COVID-19

Pandemic: A Calculator, CEPR, https://voxeu.org/article/startup-employment-calculatorcovid-19;

[21] Subramanian, S., Mohamed, S., Khanzadah, T. (2020), The Coronavirus' Impact on Education - School Students' Perspective; International Journal of Nutrition, Pharmacology, Neurological Diseases 10(3), pp. 166-167;

[22] The Romanian Trade Registry (Oficiul Național al Registrului Comerțului), 2021. Statistics- Registrations (Statistici-Înmatriculări persoaane fizice și juridice). Available at: https://www.onrc.ro/index.php/ro/statistici;

[23] Tulenko, K. \& Vervoort, D. (2020), Cracks in the System: The Effects of the Coronavirus Pandemic on Public Health Systems; American Review of Public Administration 50(6-7), pp. 455-466;

[24] Zenker, S., Kock, F. (2020), The Coronavirus Pandemic - A Critical Discussion of a Tourism Research Agenda; Tourism Management, 81,104164;

[25] Zinecker, M., Doubravský, K., Balcerzak, A. P., Pietrzak, M. B. \& Dohnal, M. (2021), The Covid-19 Disease and Policy Response to Mitigate the Economic Impact in the EU. Technological and Economic Development of Economy, 27(3), 742-762. https://doi.org/10.3846/tede.2021.14585. 